Check for updates

Cite this: RSC Adv., 2017, 7, 19645

Received 19th January 2017 Accepted 27th March 2017

DOI: $10.1039 / c 7 r a 00836 h$

rsc.li/rsc-advances

\section{Understanding the chemical state of palladium during the direct NO decomposition - influence of pretreatment environment and reaction temperature $\dagger$}

\begin{abstract}
Gunugunuri K. Reddy, D * Chen Ling, ${ }^{*}$ Torin C. Peck and Hongfei Jia
Direct decomposition of $\mathrm{NO}$ into $\mathrm{N}_{2}$ and $\mathrm{O}_{2}$ offers an ideal solution to the abatement of $\mathrm{NO}$ from automotive and various combustion processes. Although its decomposition is thermodynamically favorable $\left(\Delta \mathrm{G}=-86.6 \mathrm{~kJ} \mathrm{~mol}^{-1}\right.$ at $25^{\circ} \mathrm{C}$ ), yet kinetically hindered due to a high activation barrier of 335 $\mathrm{kJ} \mathrm{mol}^{-1}$, making use of catalyst indispensable. Supported Pd catalysts have been investigated recently for the reaction ranging from $300^{\circ} \mathrm{C}$ to $1000^{\circ} \mathrm{C}$. However, the function of palladium during the reaction at various reaction temperatures is still unclear. $\mathrm{SiO}_{2}$ supported palladium was studied as a model catalyst system for direct $\mathrm{NO}$ decomposition over temperatures ranging from 100 to $800{ }^{\circ} \mathrm{C}$ both in dynamic and steady state mode to understand the changes in the palladium chemical state with respect to the reaction temperature. Three different types of catalyst compositions of palladium namely Pd, PdO and mixture of $\mathrm{Pd}-\mathrm{PdO}$, were created on silica surface by controlling pretreatment environments for systematic comparison. Combining characterization and catalytic performance, it has been revealed that the reaction in the lower temperature region $\left(<500{ }^{\circ} \mathrm{C}\right)$, is not catalytic and $\mathrm{NO}$ chemically reacts with metallic Pd and forms PdO. The oxidation ability of metallic Pd is sensitive to the particle size of the metallic $\mathrm{Pd}$. The catalyst pretreated in helium yields $\mathrm{Pd}-\mathrm{PdO}$ composite structure and higher active metallic surface area compared to the hydrogen pretreated catalyst and exhibited higher NO conversion at lower reaction temperatures $\left(<500{ }^{\circ} \mathrm{C}\right)$. At temperatures higher than $500^{\circ} \mathrm{C}$ the $\mathrm{PdO}$ converts to metallic $\mathrm{Pd}$ by releasing oxygen, resulting in stable direct $\mathrm{NO}$ activity. Our results suggest retarding metallic Pd oxidation is key factor to develop a sustainable catalyst for direct NO decomposition at lower temperatures.
\end{abstract}

\section{Introduction}

The increase of the worldwide population has led to an increase of the energy demand and an increase of environmental pollution. Among the various pollutant gases, nitrogen oxides are considered as one of the primary pollutants of the atmosphere, since they are responsible for environmental problems like photochemical smog, acid rain, tropospheric ozone, ozone layer depletion and global warming. ${ }^{\mathbf{1} 2}$ The laws on NO emissions are increasingly strict and the research of NO abatement remains a hot topic. ${ }^{3}$ The current techniques used for the abatement of NO such as selective catalytic reduction (SCR) and non-selective catalytic reduction (NSCR) and NO storagereduction (NSR) all rely on introducing reducing agents such as ammonia, diesel soot, carbon monoxide or hydrocarbons ${ }^{4-8}$

Material Research Department, Toyota Research Institute of North America, Ann arbor MI-48105, USA.E-mail: krishna.gunugunuri@toyota.com;Chen.Ling@toyota.com $\dagger$ Electronic supplementary information (ESI) available. See DOI: 10.1039/c7ra00836h to drive the reduction of $\mathrm{NO}$ into $\mathrm{N}_{2} \cdot{ }^{9,10}$ An alternative solution for NO removal is the direct NO decomposition into harmless $\mathrm{N}_{2}$ and $\mathrm{O}_{2}$, which in principle is ideal method for the solution of NO problem.

NO is a thermodynamically unstable molecule and its decomposition into elements is favored at temperatures below $1000{ }^{\circ} \mathrm{C}^{\mathbf{1 1}}$ however, the direct decomposition is kinetically hindered due to a high activation barrier of $335 \mathrm{~kJ} \mathrm{~mol}^{-1} .^{11}$ Consequently, catalysts that help lower the kinetic barrier is essential to achieve efficient direct NO decomposition. Catalysts that have been reported to be active in the decomposition of NO can be divided into three major groups: metal oxides, zeolites, and supported metals. ${ }^{12}$ Among various direct NO catalysts, perovskites exhibit very good activity at temperatures higher than $600{ }^{\circ}$ C. $^{13}$ Recent development of rare earth and Y-Zr solid solutions and C-type rare earth oxides has marked the activity in the appropriate range for high temperature applications. ${ }^{\mathbf{1 4}}$ Although, at lower temperatures zeolites such as Cu/ZSM-5 shows the attractive activity, however, the activity is seriously inhibited by the presence of oxygen and $\mathrm{SO}_{2} \cdot{ }^{15}$ 
Despite the achievements made for direct NO decomposition at high temperatures, the development of a catalyst that works at low temperatures, which is particularly attractive for automobile emission control, has received less attention. For instance, the performance of supported noble metal catalyst, which is the commercialized component of three-way catalyst, was only addressed in a few reports for direct NO decomposition. ${ }^{16-30} \mathrm{Pt}$ based catalysts were investigated in early $20^{\text {th }}$ century and found out that the catalysts deactivates quickly at lower temperatures. ${ }^{16-19}$ Recently, studies have been focused on investigating palladium based catalysts for direct NO decomposition because of its better thermal stability and low cost compared to $\mathrm{Pt}$ based catalysts. ${ }^{20-30}$ Most of the reports concentrated on the performance of supported palladium catalyst in direct $\mathrm{NO}$ decomposition at various reaction temperatures (from $300{ }^{\circ} \mathrm{C}$ to $900{ }^{\circ} \mathrm{C}$ )..$^{20-30}$ However, a very deep understanding about the function and chemical state of the palladium during direct NO decomposition at different reaction temperatures has not been attained. For example, Baibich group $^{26-29}$ evaluated several supported and bimetallic Pd catalysts for direct NO decomposition and reported that metallic Pd catalysts deactivate with time irrespective of support and foreign metal. On the other hand, Naito et al. ${ }^{30}$ reported that metallic Pd supported on $\mathrm{SiO}_{2}$ catalyst exhibits a stable NO conversion after forming few oxygen layers on the surface. However, no effort has been made on investigating chemical state of palladium during and after the direct NO decomposition in both cases. The lack of such fundamental knowledge consequently prevents any further development or optimization. As we already know that, in three-way catalysis (TWC) the performance of the catalyst depends on the chemical state of the Pd during the reaction. ${ }^{31}$ There are several possibilities which need to be considered. Either metallic Pd or PdO is the active species or both are active species for direct NO decomposition. There may be possibility that PdO reduced to Pd metal and re-oxidizes to $\mathrm{PdO}$ in the cyclic manner. The active species may also be different at different reaction temperatures.

In the current report we present the systematic study about the mechanism of Pd catalyzed direct NO decomposition. Through analyzing the several palladium compositions, we show unambiguous evidence that the only active species for direct NO decomposition is metallic Pd. It is in sharp contrast with three-way catalyst where both metallic Pd and PdO are considered to be active. In addition, our study provides the first mechanistic understanding about direct NO decomposition at low temperatures, hence paving the road towards the development of more efficient catalyst in future.

\section{Experimental}

\subsection{Catalyst preparation}

Palladium-based catalyst supported on silica was synthesized using wet impregnation method. Before the synthesis, the silica (Cab-O-Sil EH-5 fumed silica) was treated with water at $100{ }^{\circ} \mathrm{C}$ to generate hydroxyl groups on the surface. In a typical synthesis procedure, $5 \mathrm{~g}$ of silica was mixed with $50 \mathrm{~mL}$ of water. Then the required quantity of palladium nitrate was dissolved separately in deionized water and combined with the $\mathrm{SiO}_{2}$ suspension. The mixture was heated to $80{ }^{\circ} \mathrm{C}$ with continuous stirring. The powder obtained was then dried in an oven at $120^{\circ} \mathrm{C}$ for $12 \mathrm{~h}$ under air. Finally, the catalyst was calcined at $450{ }^{\circ} \mathrm{C}$ for $3 \mathrm{~h}$ with a $1{ }^{\circ} \mathrm{C} \min ^{-1}$ ramp.

\subsection{Catalyst characterization}

2.2.1. X-ray diffraction. X-ray powder diffraction (XRD) patterns were obtained using Rigaku Smartlab X-ray diffractometer using $\mathrm{Cu} \mathrm{K} \alpha$ radiation $(\lambda=1.5405 \AA)$. A glass holder was used to support the sample. The scanning range was from $10^{\circ}$ to $80^{\circ}(2 \theta)$ with a step size of $0.02^{\circ}$ and a step time of $1 \mathrm{~s}$. The XRD phases present in the samples were identified with the help of ICDD-JCPDS $^{32}$ data files and the crystallite sizes of Pd and PdO were determined using Debye-Scherrer equation. ${ }^{33}$

2.2.2. X-ray photo electron spectroscopy. The XPS measurements were performed using PHI 5000 Versa Probe II Xray photoelectron spectrometer using an $\mathrm{Al} \mathrm{K \alpha}$ source. Charging of the catalyst samples was corrected by setting the binding energy of the adventitious carbon (C 1s) to $284.6 \mathrm{eV} .^{34}$ The XPS analysis was performed at ambient temperature and at pressures typically on the order of $10^{-7}$ Torr. Prior to the analysis, the samples were outgassed under vacuum for $30 \mathrm{~min}$.

2.2.3. CO chemisorption measurements. The active metallic surface area and particle diameter of the Pd over silica support was measured using pulse CO chemisorption method. The CO pulse chemisorption was performed by 3 flex chemi station from micromeritics. A slightly different procedure was adopted in this study compared to the conventional chemisorption procedure. The PdO completely reduce to metallic Pd initially and pulse with $\mathrm{CO}$ in the conventional pulse chemisorption procedure. In this study, the active metallic surface area and particle diameter was measured after the different pretreatments used in the direct $\mathrm{NO}$ decomposition (the pretreatment temperature for $\mathrm{O}_{2}$ is $450{ }^{\circ} \mathrm{C}$, helium is $800{ }^{\circ} \mathrm{C}$ and for hydrogen is $800{ }^{\circ} \mathrm{C}$ ) instead of completely reducing the PdO. In a typical measurement, the sample, placed in a U-shaped quartz reactor with an inner diameter of $0.5 \mathrm{~cm}$, was pretreated to required temperatures under different pretreatment environments. Then, catalysts were cooled down to $300{ }^{\circ} \mathrm{C}$ under helium flow of $50 \mathrm{~mL} \mathrm{~min}{ }^{-1}$, and maintain at this temperature for $1 \mathrm{~h}$ before further cooling to the desired temperature for chemisorption in order to clean the Pd surface and to avoid the presence of residual adsorbed gas. Pulse chemisorption was performed at $35{ }^{\circ} \mathrm{C}$. The volume of the injection loop was $0.5 \mathrm{~cm}^{3}$ and the pulses $\mathrm{CO}$ was injected in the catalytic reactor corresponding to $0.16 \mu \mathrm{mol}$ of $\mathrm{CO}$. The carrier gas was helium for CO injection (10\% CO in He, AIR LIQUIDE, 99.99\% purity). The CO consumptions were measured using TCD and the data was processed using micro active software.

2.2.4. Transmission electron microscopy (TEM) measurements. The morphology and particle size were analyzed by transmission electron microscopy (TEM) with a microscope model JEOLFEG-STEM 2010 at the acceleration voltage of 200 $\mathrm{kV}$. The samples were pretreated in the presence of oxygen, or helium or hydrogen to the required temperatures before the 
measurements. (The pretreatment temperature for $\mathrm{O}_{2}$ is $450{ }^{\circ} \mathrm{C}$, helium is $800{ }^{\circ} \mathrm{C}$ and for hydrogen is $800{ }^{\circ} \mathrm{C}$ ). After the pretreatment, the samples were dispersed in ethanol and sonicated for several hours before the measurements.

\subsection{Direct NO decomposition measurements}

The direct NO decomposition measurements were performed at atmospheric pressure in a continuous flow fixed bed quartz reactor. The $300 \mathrm{mg}$ of as-synthesized catalyst was placed in the reactor in between two glass wool plugs. All the gas flows were measured and calibrated using a digital flow meter. The reactor was heated externally via a tubular furnace regulated by a temperature controller, with a thermocouple inserted into the catalyst bed. The measurements were performed using 1\% NO balance helium with a gas hourly space velocity of $2100 \mathrm{~h}^{-1}$ and in the temperature region of $100{ }^{\circ} \mathrm{C}-800{ }^{\circ} \mathrm{C}$. Prior to the reaction, catalysts were pretreated in different environments $\left(\mathrm{O}_{2}-\right.$ $450{ }^{\circ} \mathrm{C}, \mathrm{He}-800{ }^{\circ} \mathrm{C}, \mathrm{H}_{2}-800{ }^{\circ} \mathrm{C}$ ) to investigate the effect of pretreatment environment on the activity. After the pretreatment, the bed temperature was decreased to $100{ }^{\circ} \mathrm{C}$ and direct NO decomposition measurements were collected. The reactant and product concentrations were measured using Cirrus 2 quadrupole mass spectrometer. The Ar present in the reactant stream acted as tracer of constant concentration and the $\mathrm{Ar}$ signal at $m / z=40$ was used to normalize each of the mass spectrum traces. The $100 \%$ and $0 \%$ conversion of NO was defined as the normalized mass spectrum intensity at $\mathrm{m} / z=30$ under inert flow only, and in the presence of the NO bypassing the reactor, respectively.

\section{Results and discussion}

\subsection{Characterization}

$5 \mathrm{wt} \% \mathrm{Pd}$ on $\mathrm{SiO}_{2}$ support was synthesized using wet impregnation method. After the synthesis, the catalyst was pretreated in various environments in order to create different chemical states of palladium. As expected, the catalyst pretreated with oxygen was primarily composed of oxidized phase (PdO) while the hydrogen pretreatment generated metallic $\mathrm{Pd}$, as evidenced by XRD and XPS measurements (Fig. 1 and 2). Interestingly, catalyst pretreated in inert $\mathrm{He}$ environment exhibited XRD peaks corresponding to both PdO and Pd, while XPS only showed peaks due to PdO. ${ }^{35}$ The discrepancy between XRD and XPS can be attributed to the different penetration depth of light source employed in these two techniques. While XRD is able to detect the information of the bulk phase, XPS is usually regarded as a surface technique and provides information only related to surface species. To get the bulk information using XPS, the catalyst was pre-sputtered after the hydrogen and helium pretreatment in the XPS chamber and Pd 3d spectra was measured. The Pd 3d XPS profiles after the sputtering are presented in Fig. 3. There is not much change in the Pd 3d spectra after the sputtering for the hydrogen pretreated catalyst. The catalyst exhibits peaks mainly due to Pd metal. On the other hand, the Pd 3d XPS profile of the helium pretreated catalyst is different after the sputtering. The catalyst after the sputtering

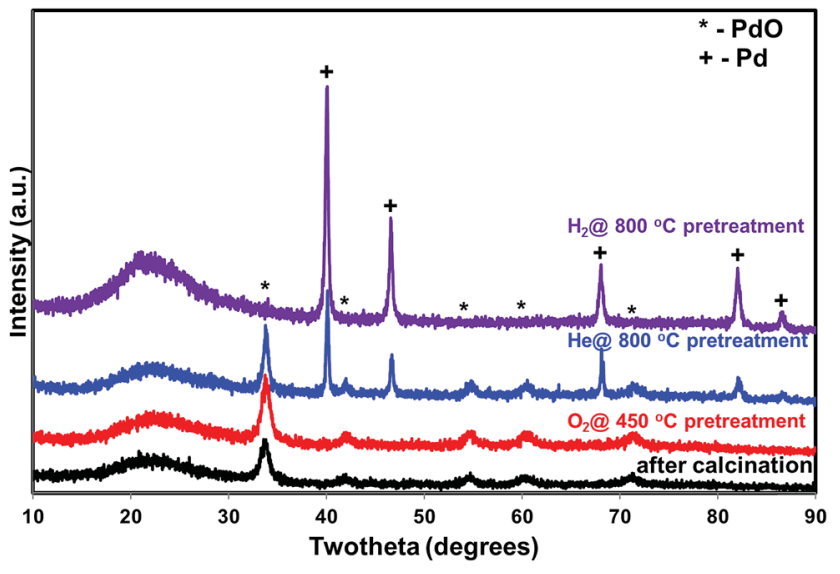

Fig. 1 X-ray diffraction of the $\mathrm{PdO} / \mathrm{SiO}_{2}$ catalyst after the calcination and after various pretreatments $\left(\mathrm{O}_{2}-450, \mathrm{He}-800, \mathrm{H}_{2}-800{ }^{\circ} \mathrm{C}\right)$.

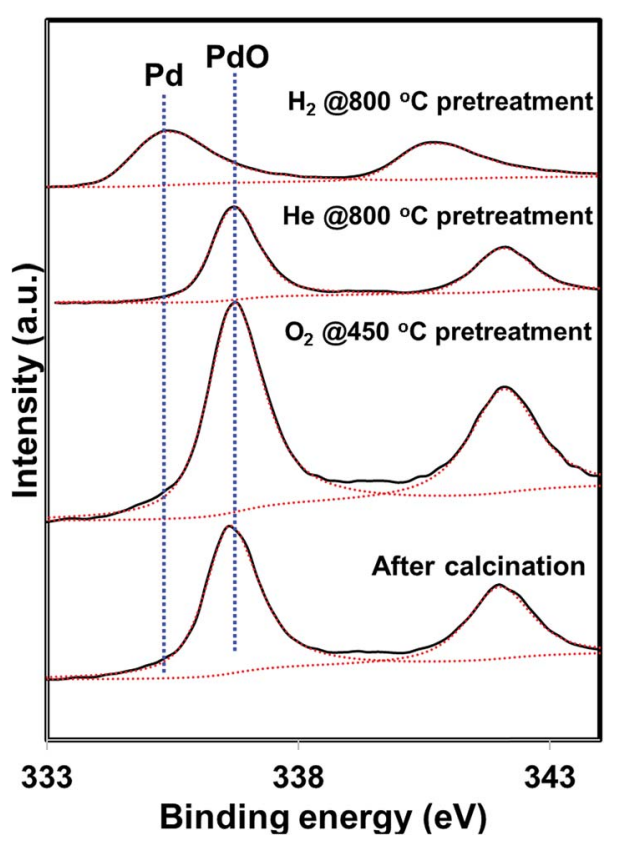

Fig. $2 \mathrm{Pd} 3 \mathrm{~d}$ XPS profiles of the $\mathrm{PdO} / \mathrm{SiO}_{2}$ catalyst after the calcination and after various pretreatments $\left(\mathrm{O}_{2}-450, \mathrm{He}-800, \mathrm{H}_{2}-800^{\circ} \mathrm{C}\right)$.

exhibits peaks due to both PdO and Pd. Hence, both XRD and Pd 3d XPS results show that there is a formation of PdO-Pd composite after the helium pretreatment where PdO is likely distributed primarily on the surface layer.

\subsection{Dynamic direct NO decomposition}

The direct NO decomposition was first performed in a dynamic reaction mode by ramping the temperature from $100-800{ }^{\circ} \mathrm{C}$ to evaluate the catalyst performance in the broad temperature region. A blank experiment was performed initially with quartz wool and silica sand in the temperature region 100 to $800{ }^{\circ} \mathrm{C}$. No activity was observed during the blank experiment. The dynamic direct NO decomposition profiles of the various pretreated $\mathrm{PdO} / \mathrm{SiO}_{2}$ catalysts with respect to the temperature are 

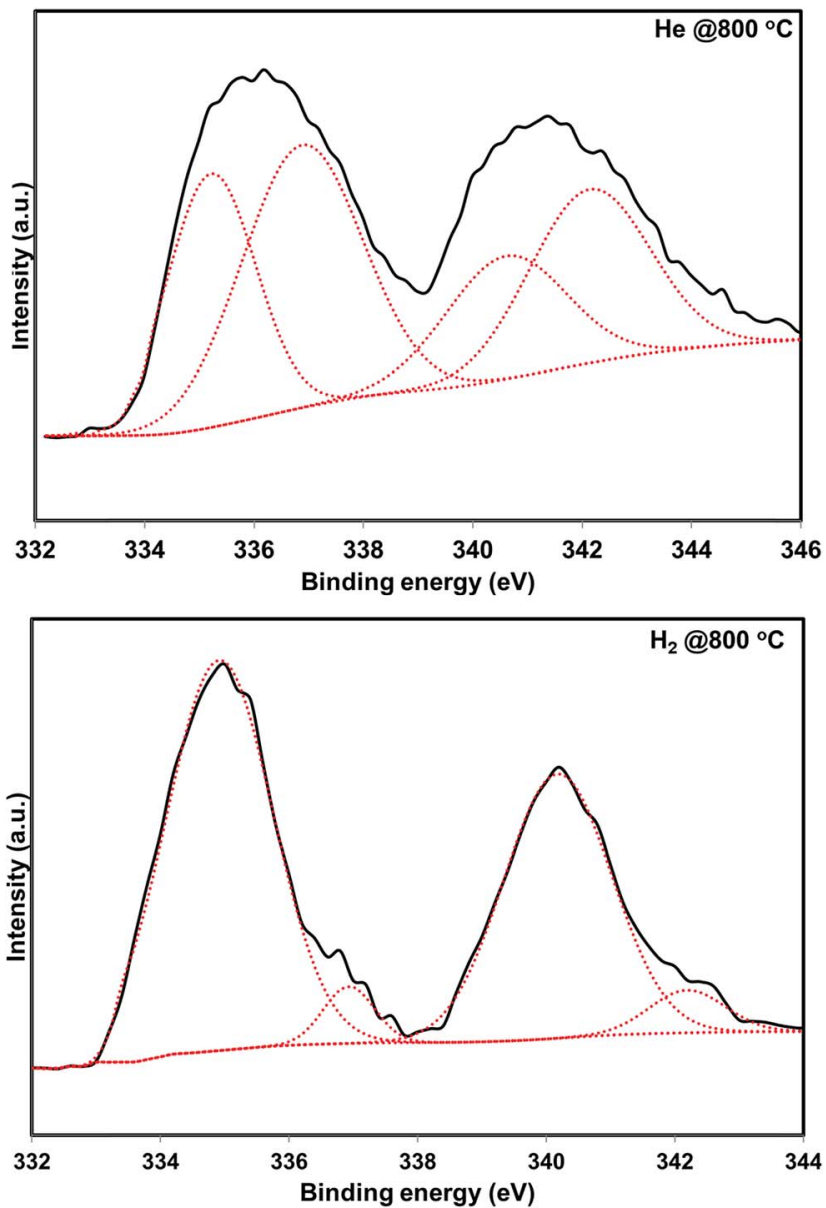

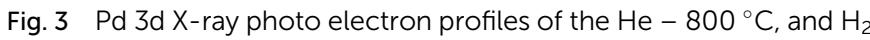
$-800{ }^{\circ} \mathrm{C}$ pretreated $\mathrm{PdO} / \mathrm{SiO}_{2}$ catalysts after pre sputtering.

presented in Fig. 4. The product distribution profiles are presented in Fig. 5. As shown in Fig. 4, the oxygen pretreated catalyst exhibited NO conversion only after $700{ }^{\circ} \mathrm{C}$ and the conversion increased with reaction temperature afterwards. The

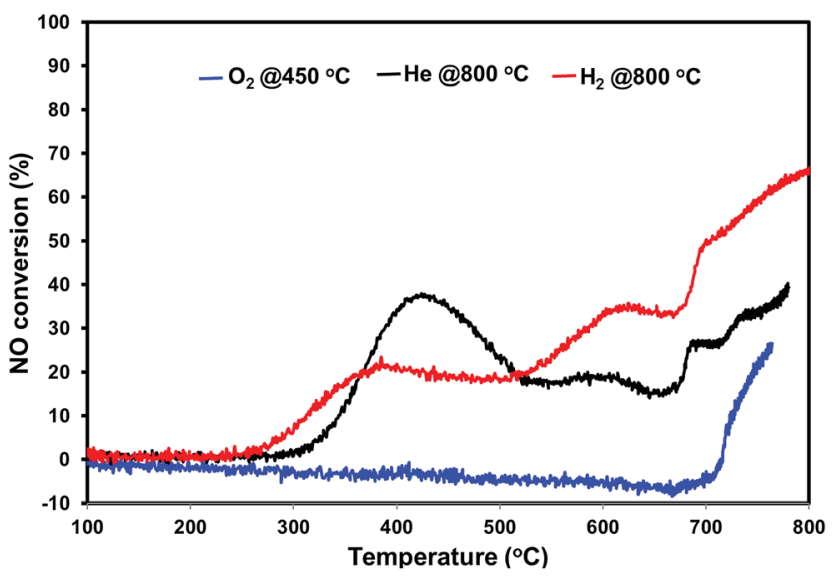

Fig. $4 \mathrm{NO}$ conversion profiles of $\mathrm{PdO} / \mathrm{SiO}_{2}$ catalyst after the pretreatment in different environments in the temperature region $100-800{ }^{\circ} \mathrm{C}\left(\mathrm{H}_{2}\right.$ pretreatment at $800{ }^{\circ} \mathrm{C}, \mathrm{O}_{2}$ pretreatment at $450^{\circ} \mathrm{C}$, He pretreatment at $800^{\circ} \mathrm{C}$ ) GHSV $-2100 \mathrm{~h}^{-1}, 1 \% \mathrm{NO}$ in helium.
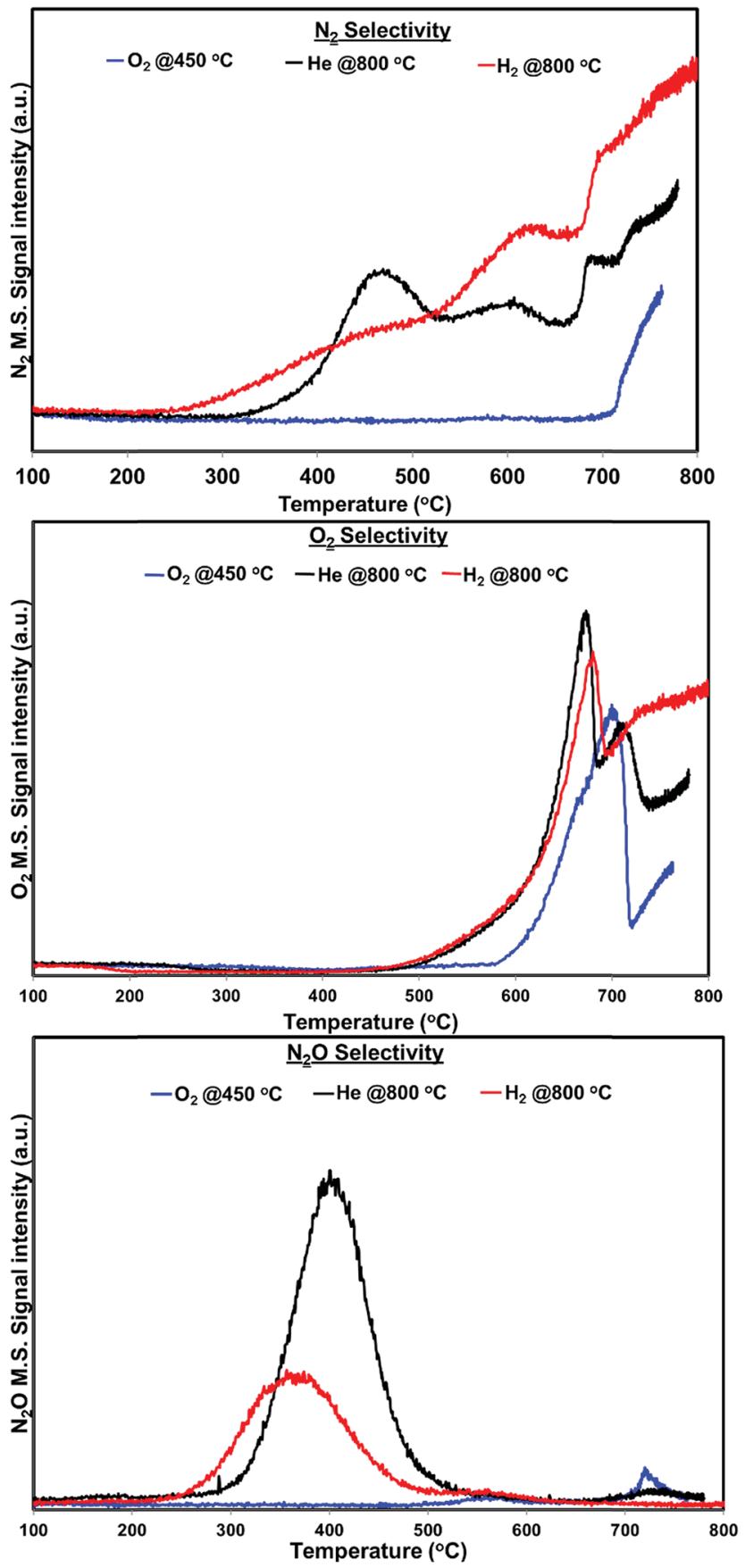

Fig. $5 \quad \mathrm{~N}_{2}, \mathrm{O}_{2}$ and $\mathrm{N}_{2} \mathrm{O}$ distribution profiles of $\mathrm{PdO} / \mathrm{SiO}_{2}$ catalyst after the pretreatment in different environments in the temperature region $100-800{ }^{\circ} \mathrm{C}\left(\mathrm{H}_{2}\right.$ pretreatment at $800{ }^{\circ} \mathrm{C}, \mathrm{O}_{2}$ pretreatment at $450{ }^{\circ} \mathrm{C}$, He pretreatment at $800^{\circ} \mathrm{C}$ ) GHSV $-2100 \mathrm{~h}^{-1}, 1 \% \mathrm{NO}$ in helium.

product distribution profiles show that the catalyst first released oxygen in the temperature region $580{ }^{\circ} \mathrm{C}-700{ }^{\circ} \mathrm{C}$ without detecting the formation of $\mathrm{N}_{2}$ or $\mathrm{N}_{2} \mathrm{O}$. After oxygen signal dropped to base line, the NO conversion started and exhibited $\mathrm{N}_{2}$ and $\mathrm{O}_{2}$ as products. In addition, small amount of $\mathrm{N}_{2} \mathrm{O}$ formation was observed at $700{ }^{\circ} \mathrm{C}$ and terminated at $720^{\circ} \mathrm{C}$. The $\mathrm{N}_{2}$ formation started from $725^{\circ} \mathrm{C}$ and increased with increasing reaction temperature. 
The NO conversion profiles of helium and hydrogen pretreated catalysts are different compared to the oxygen pretreated catalyst. As we can see from Fig. 4, the NO conversion started at $250{ }^{\circ} \mathrm{C}$ for hydrogen pretreated sample and increases with increasing reaction temperature until $380^{\circ} \mathrm{C}$. Similarly, the NO conversion for helium pretreated sample started at $300{ }^{\circ} \mathrm{C}$ and increased with increasing reaction temperature until $420{ }^{\circ} \mathrm{C}$. Then both samples exhibited a decrease in the NO conversion with reaction temperature up to $520^{\circ} \mathrm{C}$. After $520^{\circ} \mathrm{C}$, both catalysts exhibited a slight increase in the NO conversion followed by a slight decrease in the NO conversion up to $670{ }^{\circ} \mathrm{C}$. After $670{ }^{\circ} \mathrm{C}$, the $\mathrm{NO}$ conversion increases with reaction temperature for both catalysts. The helium pretreated catalyst exhibit higher NO conversion at lower reaction temperatures $\left(<500{ }^{\circ} \mathrm{C}\right)$ and hydrogen pretreated catalyst exhibit higher NO conversion at higher reaction temperatures $\left(>500{ }^{\circ} \mathrm{C}\right)$.

Fig. 4 shows the $\mathrm{N}_{2}, \mathrm{~N}_{2} \mathrm{O}$ and $\mathrm{O}_{2}$ product distribution profiles during the dynamic $\mathrm{NO}$ decomposition with respect to reaction temperature. No $\mathrm{NO}_{2}$ formation was observed in the entire temperature region for any of the pretreated catalyst. As shown in Fig. 4, the products were different at lower $\left(<500{ }^{\circ} \mathrm{C}\right)$ and higher reaction temperatures $\left(>500{ }^{\circ} \mathrm{C}\right)$ for both helium and hydrogen pretreated catalysts. $\mathrm{N}_{2}$ and $\mathrm{N}_{2} \mathrm{O}$ were observed as products at lower temperatures, and formation of $\mathrm{N}_{2}$ and $\mathrm{O}_{2}$ were observed at higher temperatures. The $\mathrm{N}_{2} \mathrm{O}$ formation was started at $260{ }^{\circ} \mathrm{C}$ for hydrogen pretreated catalyst and reached maximum at $360{ }^{\circ} \mathrm{C}$ then terminated at $460{ }^{\circ} \mathrm{C}$. Similarly, helium pretreated catalyst releases $\mathrm{N}_{2} \mathrm{O}$ from $300{ }^{\circ} \mathrm{C}$ reached maximum at $400{ }^{\circ} \mathrm{C}$ and terminated at $500{ }^{\circ} \mathrm{C}$. The $\mathrm{N}_{2}$ formation was observed followed by the $\mathrm{N}_{2} \mathrm{O}$ formation and increases with increasing the reaction temperature for both the catalysts. $\mathrm{O}_{2}$ formation started at $500{ }^{\circ} \mathrm{C}$, reached maximum at around $680{ }^{\circ} \mathrm{C}$ and went down with further increase in the temperature until $690{ }^{\circ} \mathrm{C}$ for both catalysts. After $690{ }^{\circ} \mathrm{C}$, the oxygen signal increased with increasing reaction temperature up to $800^{\circ} \mathrm{C}$ for hydrogen pretreated catalyst. However, for the helium pretreated catalyst, the oxygen signal increased slightly with increasing reaction temperature from $690{ }^{\circ} \mathrm{C}$ to $705{ }^{\circ} \mathrm{C}$ and decreased with further increase in the reaction temperature until $735{ }^{\circ} \mathrm{C}$. After $735{ }^{\circ} \mathrm{C}$ the oxygen signal increased steadily with increasing reaction temperature up to $800{ }^{\circ} \mathrm{C}$.

Based on the NO conversion and product distribution profiles of hydrogen and helium pretreated catalysts, the reaction was divided into three temperature regions i.e. low temperature $\left(300-500{ }^{\circ} \mathrm{C}\right)$, medium temperature $\left(500-700{ }^{\circ} \mathrm{C}\right)$, and high temperature (above $700^{\circ} \mathrm{C}$ ). Steady state catalytic measurements were performed at $400{ }^{\circ} \mathrm{C}, 650{ }^{\circ} \mathrm{C}$ and $800{ }^{\circ} \mathrm{C}$ over these catalysts to understand the catalyst behavior in the broad temperature region. The spent catalysts after the steady state measurements were analyzed using XRD and XPS to understand the function and chemical state of palladium during the direct NO decomposition at different reaction temperatures.

\subsection{Steady state NO decomposition measurements}

3.3.1. Steady state measurement at $400{ }^{\circ} \mathrm{C}$. Steady state NO decomposition measurements were performed at $400{ }^{\circ} \mathrm{C}$ for 2 hours to understand the catalyst role below $500{ }^{\circ} \mathrm{C}$. To keep the consistency with dynamic conversion profile, first we ramped the temperature from $100{ }^{\circ} \mathrm{C}$ to $400{ }^{\circ} \mathrm{C}$ and then performed steady state at $400{ }^{\circ} \mathrm{C}$. The NO conversion and product distribution profiles are presented in Fig. 6 and 7, respectively. Interestingly, the NO conversion reached $0 \%$ within first $30 \mathrm{~min}$ of the reaction irrespective of pretreatment. Both $\mathrm{N}_{2}$ and $\mathrm{N}_{2} \mathrm{O}$ were observed as products during the steady state measurement. In accordance with the dynamic reaction profile, no $\mathrm{O}_{2}$ formation was observed during the steady state at $400{ }^{\circ} \mathrm{C}$. Fig. 8 and 9 shows the XRD and Pd 3d XPS profiles of the spent catalysts after the steady state at $400{ }^{\circ} \mathrm{C}$. Both hydrogen and helium pretreated catalysts exhibited reflections due to both PdO and metallic Pd after the steady state at $400{ }^{\circ} \mathrm{C} .{ }^{32}$ The intensities of PdO reflections increased and metallic Pd reflections decreased after the steady state at $400{ }^{\circ} \mathrm{C}$ for helium pretreated catalyst compared to the catalyst after the pretreatment in helium. The Pd 3d XPS profiles exhibit mainly peaks due to PdO after the steady state at $400{ }^{\circ} \mathrm{C}^{.34}$ Both XRD and XPS measurements show that surface metallic Pd converted PdO during the steady state at $400{ }^{\circ} \mathrm{C}$ for both hydrogen and helium pretreated catalysts.

3.3.2. Steady state measurement at $650{ }^{\circ} \mathrm{C}$. As shown in Fig. 4, the second increase in the NO conversion started at $500{ }^{\circ} \mathrm{C}$ and reached maximum at $630{ }^{\circ} \mathrm{C}$ followed by a slight
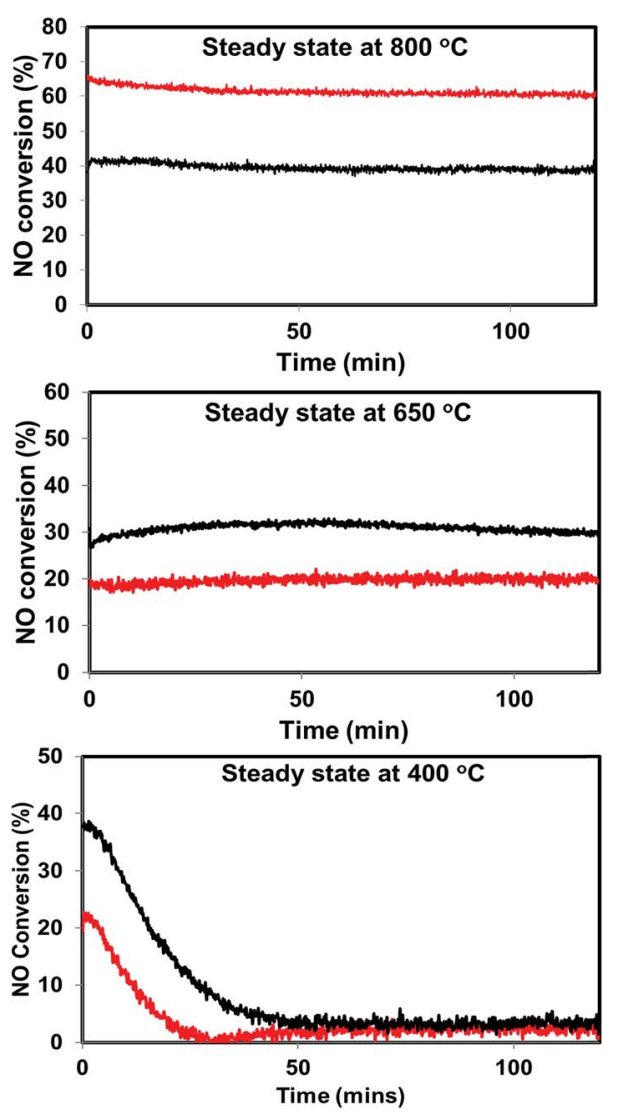

Fig. 6 Steady state activity measurements over $\mathrm{He}-800{ }^{\circ} \mathrm{C}, \mathrm{H}_{2}-$ $800{ }^{\circ} \mathrm{C}$ pretreated $\mathrm{PdO} / \mathrm{SiO}_{2}$ catalysts at $400^{\circ} \mathrm{C}, 650{ }^{\circ} \mathrm{C}$, and $800^{\circ} \mathrm{C}$ (black: helium pretreated, red: hydrogen pretreated). 

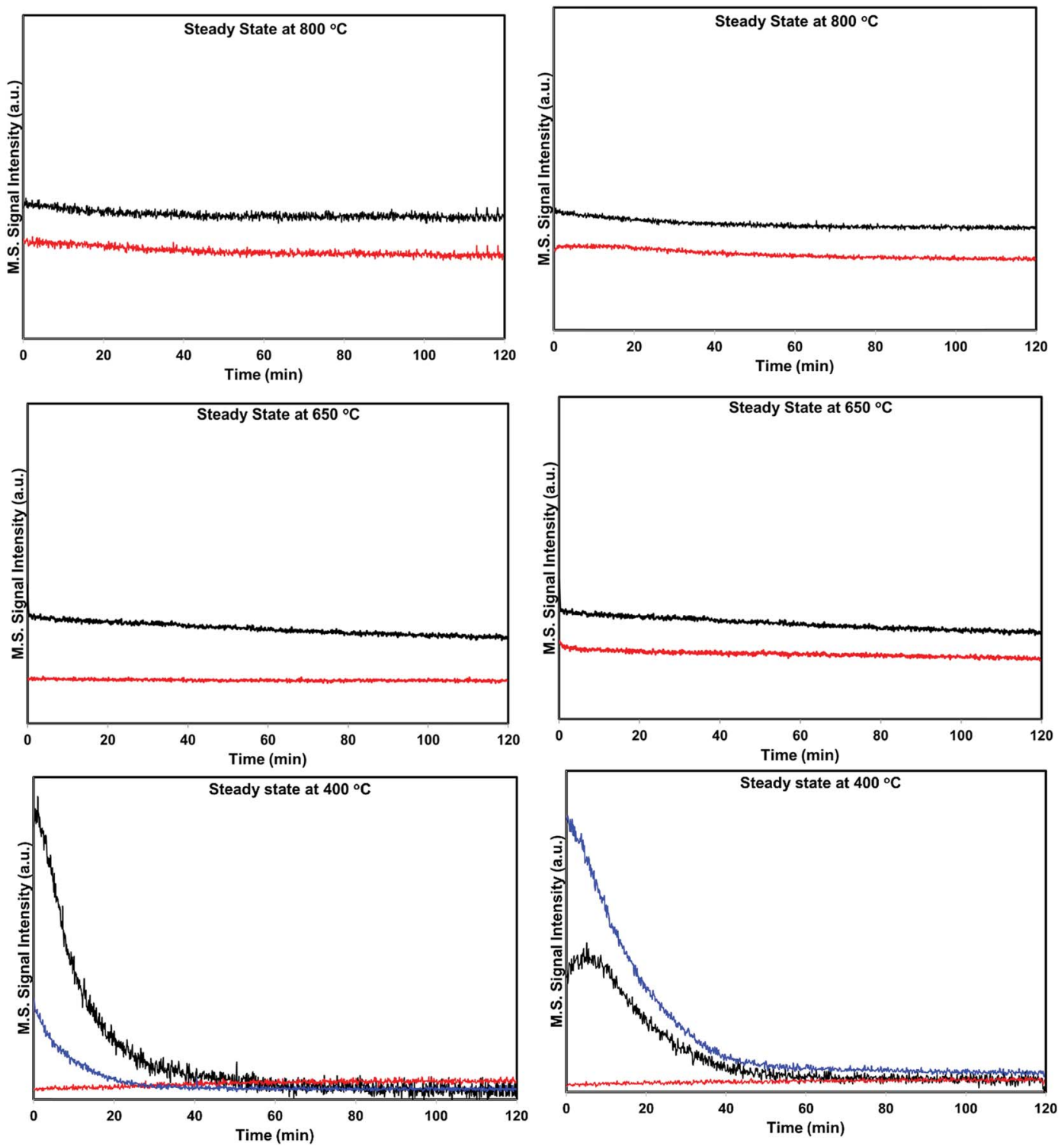

Fig. 7 Product distribution profiles of $\mathrm{N}_{2}, \mathrm{~N}_{2} \mathrm{O}$ and $\mathrm{O}_{2}$ during the steady state activity measurements at $400{ }^{\circ} \mathrm{C}, 650{ }^{\circ} \mathrm{C}$, and $800{ }^{\circ} \mathrm{C}$ over $\mathrm{He}-$ $800{ }^{\circ} \mathrm{C}, \mathrm{H}_{2}-800^{\circ} \mathrm{C}$ pretreated $\mathrm{PdO} / \mathrm{SiO}_{2}$ catalysts (black: $\mathrm{N}_{2}$, red: $\mathrm{O}_{2}$, blue: $\mathrm{N}_{2} \mathrm{O}$ ) (left: $\mathrm{H}_{2}$ pretreated catalyst, right: helium pretreated catalyst).

decrease from $630{ }^{\circ} \mathrm{C}$ to $680{ }^{\circ} \mathrm{C}$ for both helium and hydrogen pretreated catalysts. The product distribution measurements show that (Fig. 5), $\mathrm{N}_{2} \mathrm{O}$ formation terminated in this region and $\mathrm{O}_{2}$ formation started. Steady state measurements were performed at $650{ }^{\circ} \mathrm{C}$ to understand the oxygen release phenomena in the medium reaction temperature region. Fig. 6 and 7 shows the NO conversion and product distribution profiles at $650{ }^{\circ} \mathrm{C}$ for both hydrogen and helium pretreated catalysts. First we ramped the temperature from $100{ }^{\circ} \mathrm{C}$ to $650{ }^{\circ} \mathrm{C}$ and then performed steady state at $650{ }^{\circ} \mathrm{C}$ for 2 hours to keep consistency with the dynamic NO conversion profile. Interestingly, both helium and hydrogen pretreated catalysts exhibit a stable NO conversion for 2 hours of time on stream and $\mathrm{N}_{2}$ and $\mathrm{O}_{2}$ were observed as products (Fig. 8). The XRD and Pd $3 \mathrm{~d}$ XPS profiles of the spent catalysts after the steady state at $650{ }^{\circ} \mathrm{C}$ are presented in Fig. 8 and 9. The hydrogen pretreated catalysts after the steady state reaction at $650{ }^{\circ} \mathrm{C}$, exhibits peak due to metallic Pd and PdO in the X-ray diffraction pattern and Pd 3d XPS profile. However, the PdO peaks intensity decreased compared to the spent catalyst at $400{ }^{\circ} \mathrm{C}$ steady state. Similarly, the helium pretreated catalyst also exhibits peaks due to the metallic Pd and PdO.

3.3.3. Steady state measurement at $800{ }^{\circ} \mathrm{C}$. Steady state measurements were also conducted at $800{ }^{\circ} \mathrm{C}$, to understand the catalyst involvement in the high temperature region $(>700$ ${ }^{\circ} \mathrm{C}$ ) and spent catalyst characterization was done using XRD and XPS techniques. The profiles are presented in Fig. 6-9. As expected both helium and hydrogen pretreated catalysts exhibit a stable NO conversion for two hours with $\mathrm{N}_{2}$, and $\mathrm{O}_{2}$ as products. Both XRD and Pd 3d XPS profiles exhibit peaks due to only metallic Pd after the steady state at $800{ }^{\circ} \mathrm{C} .^{32,34}$ 

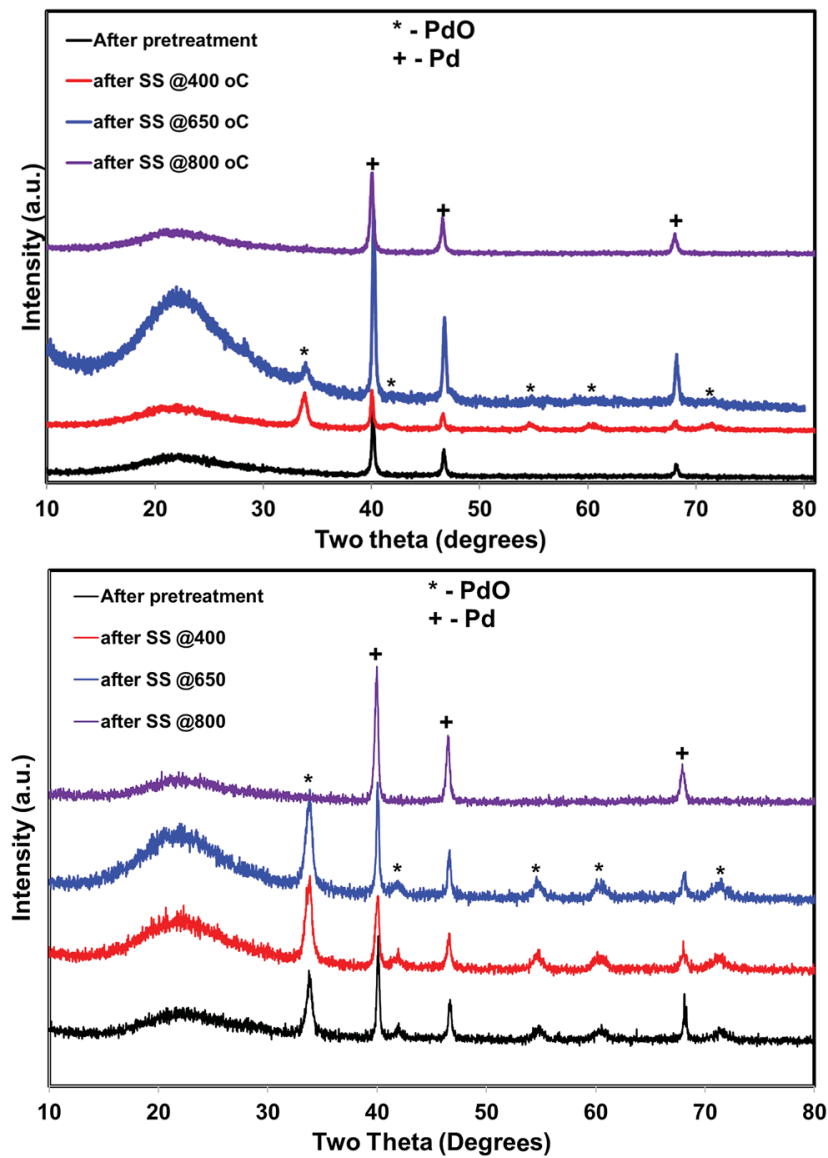

Fig. 8 X-ray diffraction profiles of the $\mathrm{He}-800{ }^{\circ} \mathrm{C}, \mathrm{H}_{2}-800{ }^{\circ} \mathrm{C}$ pretreated $\mathrm{PdO} / \mathrm{SiO}_{2}$ catalysts after steady state activity measurements at $400{ }^{\circ} \mathrm{C}, 650{ }^{\circ} \mathrm{C}$, and $800^{\circ} \mathrm{C}$ (top: hydrogen pretreated catalyst, bottom: helium pretreated catalyst).
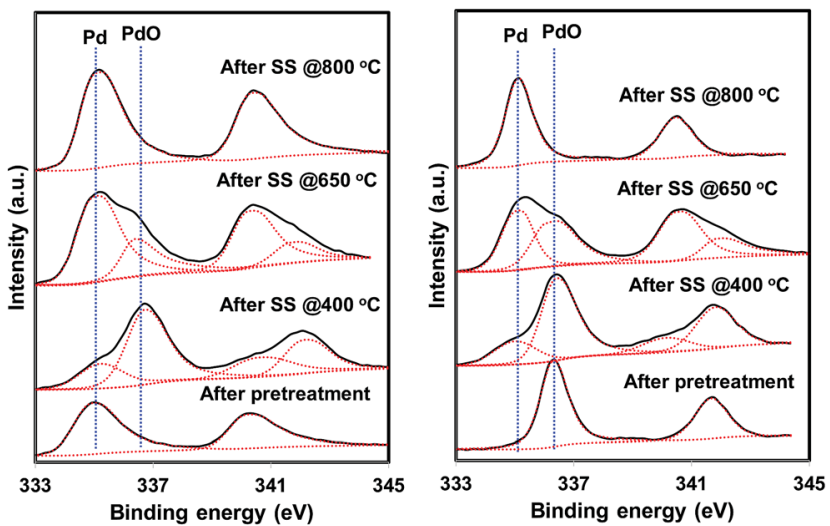

Fig. $9 \mathrm{Pd} 3 \mathrm{~d} X P S$ profiles of the $\mathrm{He}-800{ }^{\circ} \mathrm{C}, \mathrm{H}_{2}-800^{\circ} \mathrm{C}$ pretreated $\mathrm{PdO} / \mathrm{SiO}_{2}$ catalysts after steady state activity measurements at $400{ }^{\circ} \mathrm{C}$, $650{ }^{\circ} \mathrm{C}$, and $800^{\circ} \mathrm{C}$ (left: hydrogen pretreated catalyst, right: helium pretreated catalyst).

\subsection{Chemical state-activity relationship}

The chemical state of Pd during the reaction was well defined in three-way catalysis (TWC) and the performance of the catalyst strongly depends on the chemical state of Pd in TWC. ${ }^{31}$
Different active Pd species like PdO, metallic Pd, pseudo metallic $\operatorname{Pd}(\operatorname{Pd}(\mathrm{I}))$ were reported by different groups for threeway catalysis. Fernández-García $e t a l{ }^{36}$ reported that presence of hydrocarbon and the support stabilizes the Pd species with average oxidation state as $\operatorname{Pd}(\mathrm{I})$ which retains a certain metalliclike character due to the existence of Pd-Pd bonds. Liu et al. ${ }^{37}$ described that the fresh catalyst with fully oxidized Pd is quickly reduced to the metallic $\mathrm{Pd}$, and this $\operatorname{Pd}(0)$ species remains within the whole temperature range regardless of the air/fuel ratio. Iglesias-Juez et al. ${ }^{38}$ performed reaction under cycling conditions with $5 \% \mathrm{CO}$ and $5 \%\left(\mathrm{NO}+\mathrm{O}_{2} ; 1: 4.5\right)$ gas mixtures and found that both $\operatorname{Pd}(0)$ and $\operatorname{Pd}(\mathrm{I})$ can be present upon the $\mathrm{CO}$ reducing step of the $\mathrm{CO} /\left(\mathrm{NO}+\mathrm{O}_{2}\right)$ cycle, but it is strongly dependent on the loading and particle size of the Pd. In the review article by wang et al. stated that "Although the fully oxidized Pd can be the active phase for a fresh catalyst, the continuous existence of reduced Pd should be considered during the real working conditions because of the presence of $\mathrm{CO}$ and hydrocarbons in the three-way catalysis". ${ }^{31}$

The reaction conditions are different in the direct NO decomposition compared to the three-way catalysis. Here we have only one reactant NO without any reducing agent. The catalyst pretreated in $\mathrm{O}_{2}$ at $450{ }^{\circ} \mathrm{C}$ which has only PdO over the silica surface did not exhibit any activity until $700{ }^{\circ} \mathrm{C}$. Also, the catalyst releases oxygen in the temperature region $580{ }^{\circ} \mathrm{C}$ to $720^{\circ} \mathrm{C}$ first and then started to exhibit NO conversion. The PdO/ $\mathrm{SiO}_{2}\left(\mathrm{O}_{2}\right.$ at $\left.450{ }^{\circ} \mathrm{C}\right)$ spent catalyst after the dynamic direct NO decomposition contains mixture of $\mathrm{PdO}$ and $\mathrm{Pd}$ on silica surface. These results showed that during the oxygen release in the temperature region $580{ }^{\circ} \mathrm{C}$ to $720{ }^{\circ} \mathrm{C}$, the PdO converted to metallic Pd and the direct NO decomposition activity observed after the $700{ }^{\circ} \mathrm{C}$ was mainly due to the metallic Pd. These observations show that only metallic Pd is the active component for direct NO decomposition and PdO is not active unlike TWC where both oxidized and metallic Pd are active components. ${ }^{31}$

The situation is different for helium and hydrogen pretreated catalysts where palladium composition is different before the reaction. The catalyst exhibits PdO-Pd composite structure after the helium pretreatment and metallic Pd particles after the hydrogen pretreatment. The dynamic NO conversion measurements show that both helium and hydrogen pretreated catalysts started to exhibit NO conversion around $250^{\circ} \mathrm{C}-300^{\circ} \mathrm{C}$ and the $\mathrm{NO}$ conversion increases with increasing reaction temperature up to $400{ }^{\circ} \mathrm{C}$. The further increase in the reaction temperature up to $500{ }^{\circ} \mathrm{C}$ leads to a decrease in the NO conversion. The product distribution profiles show only $\mathrm{N}_{2}$ and $\mathrm{N}_{2} \mathrm{O}$ as products in this temperature region and no oxygen release was observed. The steady state time on stream measurements at $400{ }^{\circ} \mathrm{C}$ show that the NO conversion reaches to zero with in the first $20 \mathrm{~min}$ of the reaction irrespective of the pretreatment. X-ray diffraction patterns of the spent catalysts after the steady state at $400{ }^{\circ} \mathrm{C}$ show reflections due to the mixture of oxidized and metallic Pd. The Pd 3d XPS profiles show peaks mainly due to the oxidized Pd for both helium and hydrogen pretreated spent catalysts after the steady state at $400{ }^{\circ} \mathrm{C}$. Hence, the activity and characterization measurements suggest that most of the surface metallic Pd oxidized to PdO 
during the steady state at $400{ }^{\circ} \mathrm{C}$. The decrease in the NO conversion after some time, no oxygen release below $500{ }^{\circ} \mathrm{C}$ and formation of $\mathrm{PdO}$ after the steady state at $400{ }^{\circ} \mathrm{C}$ suggest that the NO decomposition in the lower temperature region $(<500$ ${ }^{\circ} \mathrm{C}$ ) is a chemical reaction between metallic Pd and NO instead of catalytic decomposition on the surface of $\mathrm{Pd} / \mathrm{SiO}_{2}$.

The characterization measurements show the $100 \%$ metallic Pd formation after the hydrogen pretreatment and PdO-Pd composite formation after the helium pretreatment. The above observation conforms that most of the NO conversion in the lower temperature region is due to the oxidation of metallic Pd to the PdO. However, helium pretreated catalyst exhibit higher NO conversion (40\%) compared to the hydrogen pretreated catalyst $(20 \%)$ in the lower temperature region. Additional characterization measurements were performed to understand the interesting behavior of helium pretreated catalyst. The morphology of the palladium particles was measured using transmission electron microscope (TEM) after the various pretreatments. The TEM images of the fresh and various pretreated $\mathrm{PdO} / \mathrm{SiO}_{2}$ catalysts are presented in Fig. 10. As expected, the fresh catalyst after the calcination exhibit small spherical PdO particles $(10-20 \mathrm{~nm})$ over the silica surface. There is not much change in the morphology and particle size of PdO after the pretreatment in oxygen at $450{ }^{\circ} \mathrm{C}$. On the other hand, agglomeration of Pd metal particles was observed after the hydrogen pretreatment and the Pd metal particles are more than $1 \mu \mathrm{m}$ in size. Interestingly, the catalyst exhibit particle sizes between $50-150 \mathrm{~nm}$ after the helium pretreatment. The crystallite sizes of PdO and metallic Pd after various pretreatment were also measured using Debye-Scherrer equation ${ }^{33}$ from the X-ray diffraction patterns and presented in Table 1. In accordance with the TEM measurements, the crystallite size of metallic Pd is much higher after the hydrogen pretreatment compared to the helium pretreatment.

To complement the particle size measurements, active particle diameter and active metallic surface of metallic Pd
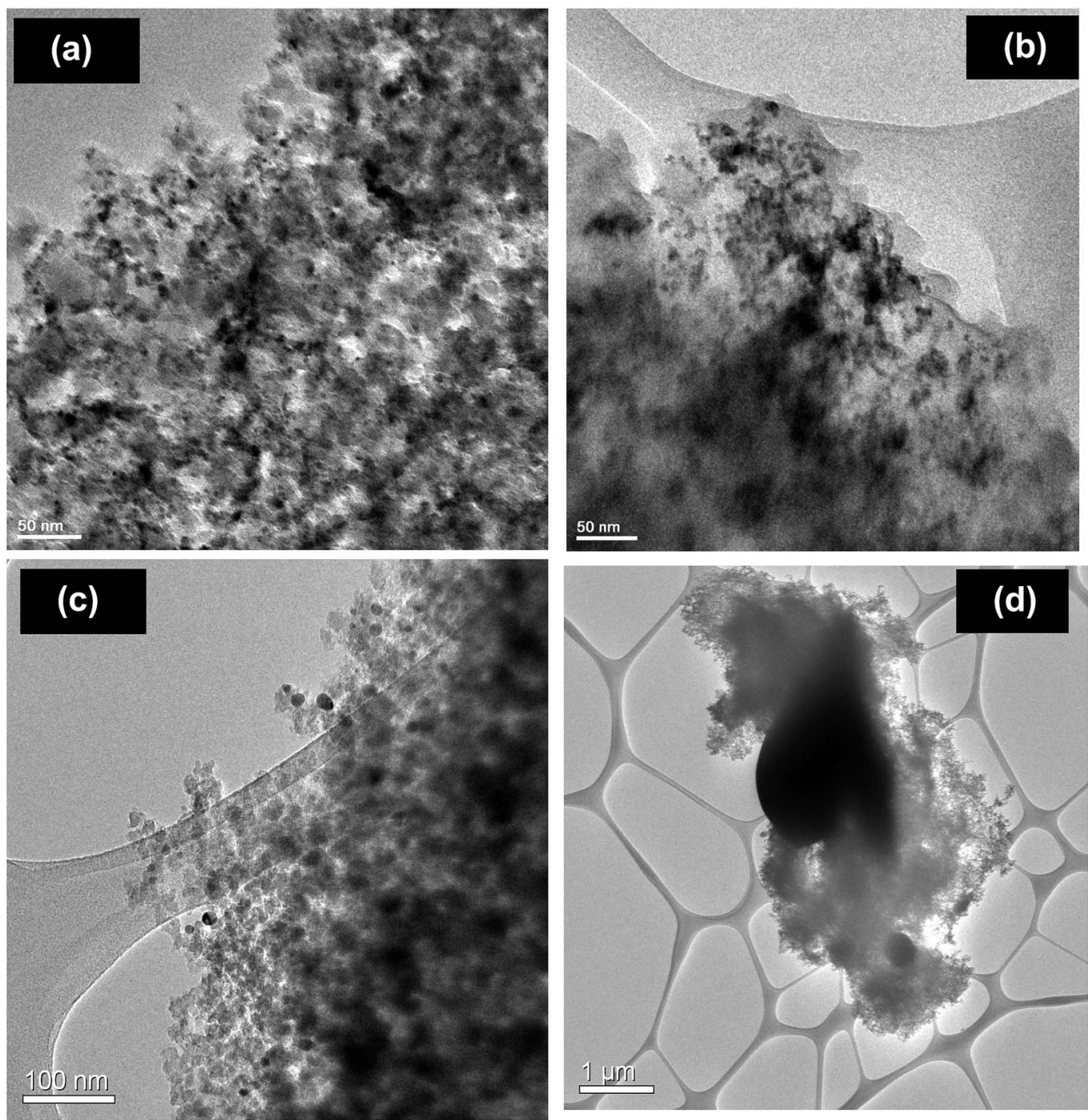

Fig. 10 TEM images of the fresh and various pretreated $\mathrm{PdO} / \mathrm{SiO}_{2}$ catalysts (a) after calcination (b) after $\mathrm{O}_{2}-450{ }^{\circ} \mathrm{C}$ pretreatment (c) after $\mathrm{He}-$ $800{ }^{\circ} \mathrm{C}$ pretreatment (d) after $\mathrm{H}_{2}-800{ }^{\circ} \mathrm{C}$ pretreatment. 
Table 1 Particle size, crystallite size, active metallic surface area, active particle diameter of the $\mathrm{PdO} / \mathrm{SiO} \mathrm{O}_{2}$ catalyst after the calcination and after various pretreatments $\left(\mathrm{O}_{2}-450, \mathrm{He}-800, \mathrm{H}_{2}-800^{\circ} \mathrm{C}\right)$

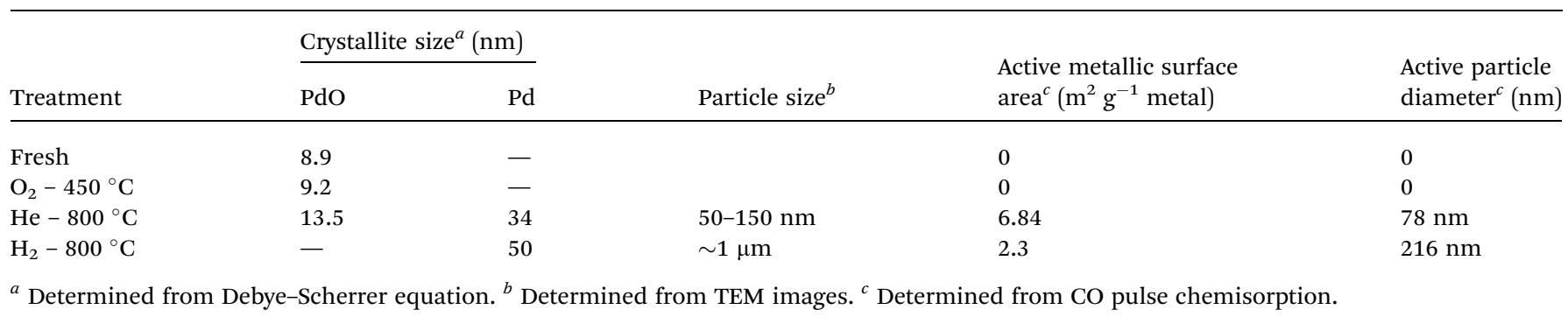

particles were measured using $\mathrm{CO}$ pulse chemisorption experiment (Table 1). As explained in experimental section, slightly different method was adopted in the present study. The pulse CO chemisorption experiments were performed after the various pretreatments. As expected, both fresh and oxygen pretreated catalysts did not consume any $\mathrm{CO}$ during the pulse experiment. As shown in Table 1, the catalyst after the helium pretreatment exhibits three times higher metallic surface area compared to the hydrogen pretreated catalyst. Both particle size and pulse chemisorption experiments show that formation of PdO-Pd composite resist the sintering of metallic Pd particles during the helium pretreatment and yield higher active metallic surface area compared to the hydrogen pretreated catalyst and exhibit higher NO conversion in the lower reaction temperature region $\left(>500^{\circ} \mathrm{C}\right)$.

To further confirm the sintering phenomena, the $\mathrm{PdO} / \mathrm{SiO}_{2}$ was pretreated at $300{ }^{\circ} \mathrm{C}$ in the presence of hydrogen and performed direct NO decomposition. The dynamic NO decomposition profiles of the $\mathrm{He}-800{ }^{\circ} \mathrm{C}, \mathrm{H}_{2}-800{ }^{\circ} \mathrm{C}$ and $\mathrm{H}_{2}-300{ }^{\circ} \mathrm{C}$ catalysts are presented in Fig. 11. The catalysts pretreated at $300{ }^{\circ} \mathrm{C}$ exhibits higher NO conversion compared to the catalyst pretreated at $800{ }^{\circ} \mathrm{C}$ in the lower temperature region $\left(<500{ }^{\circ} \mathrm{C}\right)$. TEM measurements suggest that the catalyst pretreated at $300{ }^{\circ} \mathrm{C}$ exhibit lesser metallic Pd particle size compared to the catalyst pretreated at $800{ }^{\circ} \mathrm{C}$ (not shown). On the whole activity

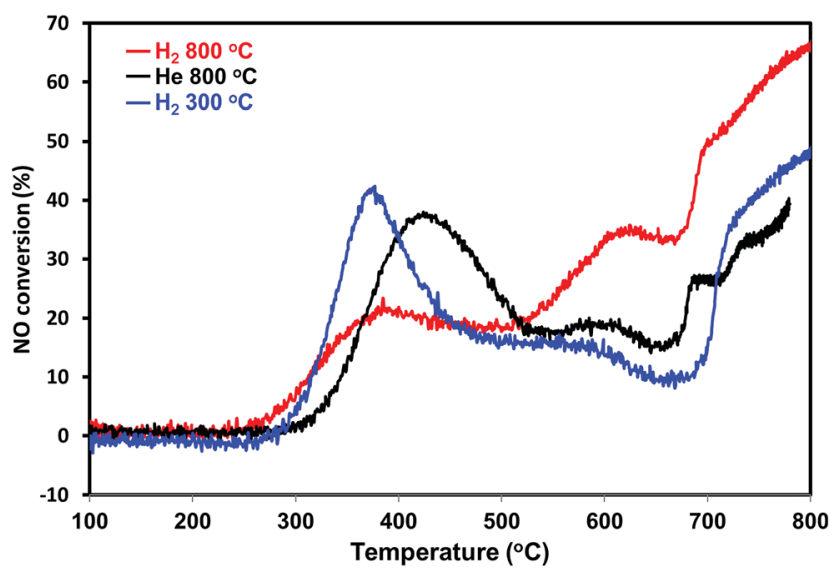

Fig. $11 \mathrm{NO}$ conversion profiles of $\mathrm{PdO} / \mathrm{SiO}_{2}$ catalyst after $\mathrm{He}-$ $800{ }^{\circ} \mathrm{C}, \mathrm{H}_{2}-300{ }^{\circ} \mathrm{C}, \mathrm{H}_{2}-800{ }^{\circ} \mathrm{C}$ pretreatments in the temperature region $100-800{ }^{\circ} \mathrm{C}\left(\mathrm{GHSV}-2100 \mathrm{~h}^{-1}, 2 \% \mathrm{NO}\right.$ in helium). and characterization measurements show that the NO decomposition activity over $\mathrm{PdO} / \mathrm{SiO}_{2}$ catalyst at lower reaction temperature $\left(<500^{\circ} \mathrm{C}\right)$ is mainly due to the oxidation of metallic Pd to PdO and the activity is sensitive to the metallic Pd particle size.

As explained above, most of the surface metallic Pd oxidized to PdO during NO decomposition at low temperature $\left(<500^{\circ} \mathrm{C}\right)$ for both helium and hydrogen pretreated catalysts. The dynamic product distribution measurements show that both helium and hydrogen pretreated catalysts releases oxygen between $500{ }^{\circ} \mathrm{C}$ and $700{ }^{\circ} \mathrm{C}$ like oxygen pretreated catalyst. The oxygen release is due to the formation of metallic Pd from PdO formed during the low temperature reaction. The reduction of PdO to metallic Pd occurred in one stage for hydrogen pretreated catalyst and two stages for helium pretreated catalyst. This may be due to the presence of two types PdO in the helium pretreated catalyst (PdO in the PdO-Pd composite structure and PdO formed from oxidation of metallic Pd to PdO during the low temperature direct NO decomposition).

The steady state activity measurements at $650{ }^{\circ} \mathrm{C}$ show that both helium and hydrogen pretreated catalysts exhibit stable $\mathrm{NO}$ conversion for 2 hours with both $\mathrm{N}_{2}$ and $\mathrm{O}_{2}$ as products. The XRD and Pd 3d X-ray photo electron spectra of exhibit peaks due to both PdO and metallic Pd after the steady state at $650{ }^{\circ} \mathrm{C}$. These results show PdO releases oxygen and convert to metallic Pd after $500{ }^{\circ} \mathrm{C}$ and the NO conversion in this temperature region is mainly due to the Pd-PdO oxidation-reduction cycle. The Pd metal reacts with NO and forms PdO and then PdO release oxygen and convert to Pd metal.

The dynamic NO conversion profiles show that all the PdO converted to metallic Pd by $700{ }^{\circ} \mathrm{C}$ for the hydrogen pretreated catalyst, whereas it extended to $750^{\circ} \mathrm{C}$ for the helium pretreated catalyst. Steady state measurements at $800{ }^{\circ} \mathrm{C}$ exhibit a stable NO conversion with $\mathrm{N}_{2}$ and $\mathrm{O}_{2}$ as products. The XRD and Pd 3d XPS profiles exhibit presence of only metallic Pd after the steady state at $800{ }^{\circ} \mathrm{C}$. These results show that NO directly decomposes into $\mathrm{N}_{2}$ and $\mathrm{O}_{2}$ on metallic Pd surface in this temperature region without any oxidation. The complete reaction mechanism in a broad temperature region $\left(100-800{ }^{\circ} \mathrm{C}\right)$ over both helium and hydrogen pretreated catalyst in presented in Scheme 1.

Iglesias-Juez et al. $^{38}$ reported that the performance and chemical state of Pd strongly depends on the Pd loading in TWC. They observed different chemical states for different 


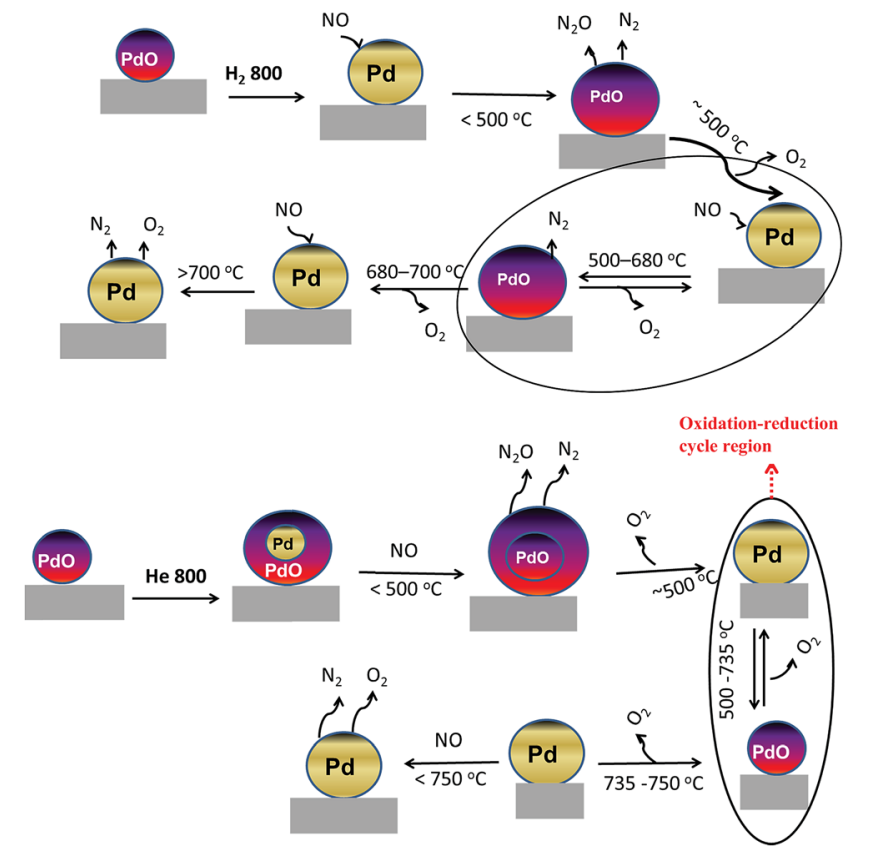

Scheme 1 Mechanism of the direct $\mathrm{NO}$ decomposition over $\mathrm{PdO} /$ $\mathrm{SiO}_{2}$ catalysts in low, medium and high temperature regions over hydrogen and helium pretreated catalysts.

loading of Pd on alumina support. The influence of Pd loading on the oxygen release temperature of $\mathrm{PdO} / \mathrm{SiO}_{2}$ has been investigated. For this purpose, $0.5,1$ and $3 \mathrm{wt} \%$ of palladium was deposited over silica support and compared with $5 \mathrm{wt} \%$ $\mathrm{PdO} / \mathrm{SiO}_{2}$ catalyst. The oxygen product distribution profiles of the various Pd loaded $\mathrm{SiO}_{2}$ catalysts are presented in Fig. 12 . The samples were pretreated in the presence of hydrogen at $300{ }^{\circ} \mathrm{C}$ before the reaction. All the samples exhibit oxidation of metallic Pd to PdO irrespective of Pd loading in the lower reaction temperature region. Interestingly, there is not much change in the PdO to metallic Pd reduction temperature with changing Pd loading (Fig. 12). The oxygen signal intensity increases with increasing Pd loading. This is due to higher

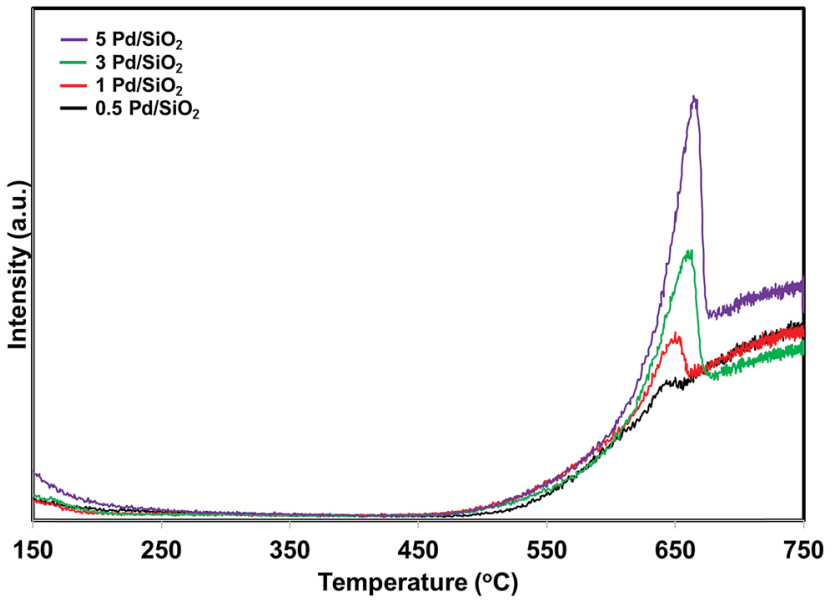

Fig. $12 \mathrm{O}_{2}$ product release profiles of the $\mathrm{PdO} / \mathrm{SiO}_{2}$ catalysts with different $\mathrm{PdO}$ loadings during direct $\mathrm{NO}$ decomposition. amount of metallic Pd oxidation to PdO in the lower reaction temperature region.

Our study shows that the mechanism of the direct NO decomposition is different than the three-way catalysis. In three-way catalysis both PdO and metallic Pd are active components for the reaction. Only metallic Pd is active for the direct NO decomposition. In three-way catalysis the chemical state of palladium (Pd(II) or $\operatorname{Pd}(\mathrm{I})$ or metallic Pd) depends on the several factors like support, Pd loading, particle size, synthesis method, promoter etc. In direct NO decomposition the chemical state of palladium strongly depends on the reaction temperature. Irrespective of pretreatment, and palladium loading most of the metallic Pd oxidized to PdO during the direct NO decomposition in the lower reaction temperature region $(<500$ ${ }^{\circ} \mathrm{C}$ ). The oxidized Pd releases oxygen after $500{ }^{\circ} \mathrm{C}$ and converted to metallic Pd. These results show that the techniques developed for three-way catalysis not necessarily work for direct NO decomposition and completely different approach needed to develop a Pd-based catalyst for direct NO decomposition in the lower reaction temperature region $\left(<500{ }^{\circ} \mathrm{C}\right)$.

\section{Conclusions}

Influence of pretreatment and reaction temperature on the mechanism of the direct NO decomposition has been investigated over $\mathrm{PdO} / \mathrm{SiO}_{2}$ model system. Our activity and characterization measurements suggest that the mechanism of the NO decomposition is completely different at lower, medium and higher reaction temperatures. At lower reaction temperatures $\left(<500{ }^{\circ} \mathrm{C}\right)$ the activity is mainly due to the oxidation of the Pd metal to PdO and the oxidation ability of Pd metal depends on the particle size and active metallic surface area. The Pd-PdO composite formation occurs during the helium pretreatment and resists the sintering of Pd metal and leads to the higher NO conversion at lower reaction temperatures compared to the hydrogen pretreated catalyst. Irrespective of pretreatment and loading, supported palladium catalysts release oxygen after $500{ }^{\circ} \mathrm{C}$ due to the reduction of the PdO to Pd metal. Then, the simultaneous oxidation-reduction cycle occurs in the medium temperature region $\left(500-680^{\circ} \mathrm{C}\right)$ and mainly responsible for the NO conversion in this region. PdO completely reduces to Pd metal after $700{ }^{\circ} \mathrm{C}$ for hydrogen pretreated catalyst and after $750{ }^{\circ} \mathrm{C}$ for helium pretreated catalyst and NO directly decomposes into $\mathrm{N}_{2}$ and $\mathrm{O}_{2}$ on the Pd metal surface and no further oxidation of Pd metal occurs.

\section{Acknowledgements}

Gunugunuri K. Reddy thank Michael jones from TRI-NA for assistance with the XPS measurements.

\section{Notes and references}

1 Z. Liu and S. L. Woo, Catal. Rev.: Sci. Eng., 2006, 48, 43.

2 A. Fritz and V. Pitchon, Appl. Catal., B, 1997, 13, 1.

3 N. Imanaka and T. Masui, Appl. Catal., A, 2012, 431-432, 1-8. 
4 D. Reichert, H. Bockhorn and S. Kureti, Appl. Catal., B, 2008, 80, 248-259.

5 T. Nakatsuji, T. Yamaguchi, N. Sato and H. Ohno, Appl. Catal., B, 2008, 85, 61-70.

6 C. He and K. Ko, Phys. Chem. Chem. Phys., 2006, 8, 898-905. 7 J. D. A. Bellido and E. M. Assaf, Fuel, 2009, 88, 1673-1679.

8 E. A. Efthimiadis, S. C. Christoforou, A. A. Nikolopoulous and L. A. Vasalos, Appl. Catal., B, 1999, 22, 91-106.

9 Z.-S. Zhang, M. Crocker, B.-B. Chen, Z.-F. Bai, X.-K. Wang and C. Shi, Catal. Today, 2015, 256, 115-123.

10 S. S. C. Chuang and C.-D. Tan, J. Phys. Chem. B, 1997, 101, 3000-3004.

11 H. Beyer and K. Kohler, Appl. Catal., B, 2010, 96, 110-116.

12 A. Fritz and V. Pitchon, Appl. Catal., B, 1997, 13, 1-25.

13 J. Zhu and A. Thomas, Appl. Catal., B, 2009, 92, 225-233.

14 H. Masaki, T. Masui and N. Imanaka, J. Alloys Compd., 2008, 451, 406-409.

15 M. Iwamoto and H. Hamada, Catal. Today, 1991, 10, 57-71.

16 J. Zawadski and G. Pertinsky, Compt. Rendus Chem., 1934, 198, 260.

17 R. R. Sakaida, R. G. Rinker, Y. L. Wang and W. H. Corcoran, AIChE J., 1961, 7, 658-663.

18 M. Shelef, K. Otto and H. Gandhi, Atmos. Environ., 1969, 3, 107-122.

19 A. Amirnazmi, J. E. Benson and M. Boudart, J. Catal., 1973, 30, 55.

20 M. Iwamotoi and H. Hamada, Catal. Today, 1991, 10, 67-71.

21 Y. F. Y. Yao, J. Catal., 1984, 87, 152-162.

22 R. J. Wu, T. Y. Chou and C. T. Yeh, Appl. Catal., B, 1995, 6, 105-116.

23 A. Ogata, A. Obuchi, K. Mizuno, A. Ohi, H. Aoyama and H. Ohuchi, Appl. Catal., 1990, 65, L11-L15.

24 Y.-J. Huang, H. P. Wang, C.-T. Yeh, C. C. Tai and C. Y. Peng, Chemosphere, 1999, 39, 2279-2287.
25 M. Haneda, Y. Kintaichi, I. Nakamura, T. Fujitani and H. Hamada, Chem. Commun., 2002, 2816-2817.

26 J. Peralta, E. V. Benvenutti, J. A. C. Ruiz, H. O. Pastore and I. M. Baibich, J. Mol. Catal. A: Chem., 2006, 246, 33-38.

27 R. M. Dallagoa and I. M. Baibich, J. Braz. Chem. Soc., 2009, 20, 873-879.

28 A. M. de Oliveira, I. M. Baibich, N. R. C. F. Machado, M. L. Mignoni and S. B. C. Pergher, Catal. Today, 2008, 133-135, 560-564.

29 A. M. de Oliveira, L. E. Crizel, R. S. da Silveira, S. B. C. Pergher and I. M. Baibich, Catal. Commun., 2007, 8, 1293.

30 S. Naito, M. Iwahashi, I. Kawakami and T. Miyao, Catal. Today, 2002, 73, 355-361.

31 J. Wang, H. Chen, Z. Hu, M. Yao and Y. Li, Catal. Rev.: Sci. Eng., 2015, 57, 79-144.

32 H. P. Klug and L. E. Alexander, X-ray Diffraction Procedures for Polycrystalline and Amorphous Materials, Wiley, New York, 2nd edn, 1974.

33 A. Patterson, Phys. Rev., 1939, 56, 978-982.

34 C. D. Wagner, W. M. Riggs, L. E. Davis, and J. F. Moulder, Handbook of X-ray Photoelectron Spectroscopy, ed. G.E. Muilenberg, Perkin-Elmer Corp., Waltham, MA, 1978.

35 G. B. Hoflund, H. A. E. Hagelin, J. F. Weaver and G. N. Sailata, Appl. Surf. Sci., 2003, 205, 102-112.

36 M. Fernández-García, A. Iglesias-Juez, A. Martínez-Arias, A. B. Hungría, J. A. Anderson, J. C. Conesa and J. Soria, J. Catal., 2004, 221, 594-600.

37 Y. Lu, M. S. Kumar, G. L. Chiarello, P. D. Eggenschwiler, C. Bach, M. Weilenmann, A. Spiteri, A. Weidenkaff and D. Ferri, Catal. Commun., 2013, 39, 55-59.

38 A. Iglesias-Juez, A. Kubacka, A. Martínez-Arias, M. Di Michiel and M. A. Newton, J. Am. Chem. Soc., 2011, 133, 4484-4489. 